\title{
OPEN Modeling and analysis of transient lubrication characteristic of the helicopter main transmission spiral bevel gears in point contacts
}

\author{
Yanzhong Wang ${ }^{1,3}$, Kai Yang ${ }^{1 凶}$, Xiaomeng $\mathrm{Chu}^{2}$, Wen Tang ${ }^{4} \&$ Changyong Huang ${ }^{3}$
}

An engineering calculation model is introduced for point-contact elastohydrodynamic lubrication analysis of spiral bevel gears. This model can analyze transient lubrication characteristics of spiral bevel gears. The influence of the angle between the lubricant entrainment and the minor axis of the contact ellipse is included in this model. The contact parameters of the spiral bevel gear are calculated, which will change with time during the meshing process. The variation of lubricant film thickness during the meshing process of spiral bevel gears is unraveled. Due to the influence of entrainment velocity, the oil film thickness at the out mesh side is smaller than that at the enter mesh side under the same contact force. It is evident that the higher the pressure is, the larger the contact area will be. Meanwhile, the thickness of the oil film is reduced, and the oil film distribution in the contact area is relatively uniform. Taking helicopter main transmission spiral bevel gears as an example, this study finally calculates the distribution characteristics of the oil film thickness of the spiral bevel gear, and solves the lubrication performance of the spiral bevel gear under different working conditions.

The elastohydrodynamic lubrication (EHL) can be applied to the study of common engineering contact elastohydrodynamic lubrication areas such as gear meshing and rolling bearings. For helicopter main transmission spiral bevel gears, high input speed and high slip speed lead to high heating of gear system. At the same time, due to the lightweight design requirements of the helicopter, the gear system is thin-walled design. When the gear teeth are poorly lubricated or the lubricating oil film is unstable, the cooling capacity of the lubricating oil will be reduced, which directly leads to the heating deformation of the system, the reduction of transmission performance, and even the transmission system failure and helicopter crash.

To consider the influence of tooth surface roughness on lubrication in actual engineering, scholars proposed a hybrid lubrication model for the lubrication performance analysis of gears. According to the description of the surface topography of the friction pair, the models are divided into two categories, which include stochastic and the deterministic model. Christensen ${ }^{1}$ proposed a stochastic model for hydrodynamic lubrication analysis between one-dimensional rough surfaces. Patir ${ }^{2}$ proposed an average flow model, which divided the lubrication area into dry contact and fluid lubrication area. Chang ${ }^{3,4}$ proposed a thermoelastic lubrication mechanism for non-Newtonian fluids, and the effect of temperature on the lubricating oil was taken into account. Venner ${ }^{5,6}$ studied the steady-state lubrication of line contact using the actual measured rough surface. The results indicated that deformation of the rough peak under load could not be ignored in lubrication analysis. $\mathrm{Ai}^{7,8}$ solved the transient lubrication problem of the three-dimensional rough surface through the use of multi-grid and incomplete system method. Based on the research of theoretical calculations of EHL, some scholars had applied this theory to the field of gear transmission.

To resolve the lubrication analysis of gear transmission, Evans et al..$^{9-11}$ measured the microscopic profile of the gear surface and studied the effect of surface microstructure on the gear lubricant film and pressure distribution. Due to the complexity of the meshing process of spiral bevel gears, fewer scholars employed the theory of hydrodynamic lubrication into the analysis of spiral bevel gear elastohydrodynamic. Simon ${ }^{12,13}$ analysed the influence of the adjustment of the processing parameters of the spiral bevel gear on its lubrication performance, and found that reasonable processing parameters could significantly enhance the bearing capacity of the elastic

\footnotetext{
${ }^{1}$ School of Mechanical Engineering, Beihang University, Beijing 100191, China. ${ }^{2}$ College of Mechanical Engineering and Automation, Liaoning University of Technology, Jinzhou 121001, China. ${ }^{3}$ Ningbo Institute of Technology, Beihang University, Ningbo 315800, China. ${ }^{4}$ China Electronics Technology Group Corporation 3rd Research Institute, Beijing 100015, China. ${ }^{\circledR}$ email: yk175yy@buaa.edu.cn
} 


\begin{tabular}{|l|l|l|l|l|l|l|}
\hline & $\boldsymbol{W}$ & $\boldsymbol{U}$ & $\boldsymbol{G}$ & $\boldsymbol{\kappa}$ & $\boldsymbol{\sigma}$ & $\boldsymbol{V}$ \\
\hline Minimum & $1.5 \times 10^{-7}$ & $1 \times 10^{-12}$ & 2500 & 1 & 0 & 0.005 \\
\hline Maximum & $2.5 \times 10^{-4}$ & $1 \times 10^{-10}$ & 7500 & 8 & $5 \times 10^{-5}$ & 0.03 \\
\hline
\end{tabular}

Table 1. Parameter range for lubrication model.

oil film of the gear. Pu and Wang ${ }^{14-17}$ examined the effects of various speed directions on the lubrication state, and discovered the analysis of the contact area friction coefficient as well as temperature field distribution. Pei ${ }^{18,19}$ predicted the wear of tooth surfaces for the spiral bevel gears, then proposed a transient mixed lubrication model and a two-dof-torsional dynamic model.

When the spiral bevel gear operated under high speed and heavy load, the mesh force might be very high near resonance compared with static condition ${ }^{20-23}$. Noted that the mesh force was an important parameter of lubrication analysis ${ }^{24,25}$. On the basis of Zaretsky model, $\mathrm{CaO}^{26,27}$ gave the contact fatigue analysis under different contact paths considering the mixed lubrication. $\mathrm{Gan}^{28}$ adopted thermal analysis finite element software to study the bulk and flash temperature of spiral bevel gears based on the mixed EHL model. Recently, Sun ${ }^{29}$ analyzed the impact of contact point migration on the results of EHL analysis.

The contact parameters (inclusive of contact force, relative speed, and radius of curvature, etc.) during the mesh of the spiral bevel gear, continually mutated with the change of the meshing position. Therefore, it is essential to note that lubrication analysis of spiral bevel gears must consider the time-varying features of the contact parameters.

In this work, the case where the minor axis of the ellipse is different from the direction of the entrainment speed of the lubricating oil is considered. Also, the case where the impact of pressure of the lubricating oil on the tooth surface lubrication under high speed and heavy load is considered. Based on the solution of point contact elastohydrodynamic lubrication model, a calculation model for the spiral bevel gear lubrication is established. Then the variation of the thickness and pressure of the lubricating oil film during the meshing of the spiral bevel gear is analyzed, and the effects of different working conditions and surface parameters on oil film thickness are also calculated.

\section{Simplified model for lubrication analysis of spiral bevel gears for engineering applications}

Simplified model of line contact and point contact hybrid lubrication analysis. The numerical solution of EHL is complex, and it costs a significant amount of time to analyze each meshing position. Dowson et al. ${ }^{30}$ proposed an empirical formula to simplify the calculation of the elastic lubrication film thickness. Masjedi et al. ${ }^{31,32}$ performed a large number of numerical calculations and fitted the calculation results into a mixed lubrication empirical formula suitable for engineering applications.

Based on these studies, expressions are derived to predict the central and minimum film thickness. The expressions also predict the asperity load ratio, which is the percentage of the load in contact (carried by the surface asperities). These formulas are summarized below, and the applicable parameter ranges are shown in Table 1.

Line-contact $\mathrm{EHL}^{31}$ (L model):

$$
\begin{gathered}
H_{c}=h_{c} / R=2.691 W^{-0.135} U^{0.705} G^{0.556}\left(1+0.2 \bar{\sigma}^{1.222} V^{0.223} W^{-0.229} U^{-0.748} G^{-0.842}\right) \\
H_{\min }=h_{\min } / R=1.652 W^{-0.077} U^{0.716} G^{0.695}\left(1+0.026 \bar{\sigma}^{1.120} V^{0.185} W^{-0.312} U^{-0.809} G^{-0.977}\right) \\
L_{a}=0.005 W^{-0.408} U^{-0.088} G^{0.103}\left[\ln \left(1+4470 \bar{\sigma}^{6.015} V^{1.168} W^{0.485} U^{-3.741} G^{-2.898}\right)\right]
\end{gathered}
$$

Point-contact $\mathrm{EHL}^{32}$ (P model):

$$
\begin{aligned}
& H_{\mathrm{c}}=h_{\mathrm{c}} / R= 3.672 W^{-0.045 \kappa^{0.18}} U^{0.663 \kappa^{0.025}} G^{0.502 \kappa^{0.064}}\left(1-0.573 e^{-0.74 \kappa}\right) \\
& \times\left(1+0.025 \bar{\sigma}^{1.248} V^{0.119} W^{-0.133} U^{-0.884} G^{-0.977} \kappa^{0.081}\right) \\
& H_{\min }=h_{\min } / R= 1.637 W^{-0.09 \kappa^{-0.15}} U^{0.711 \kappa^{-0.023}} G^{0.65 \kappa^{-0.045}}\left(1-0.974 e^{-0.676 \kappa}\right) \\
& \times\left(1+0.141 \bar{\sigma}^{1.073} V^{0.149} W^{-0.044} U^{-0.828} G^{-0.945} \kappa^{-0.395}\right) \\
& L_{a}=10 W^{-0.083} U^{0.143} G^{0.314}\left[\ln \left(1+\bar{\sigma}^{4.689} V^{0.509} W^{-0.501} U^{-2.90} G^{-2.870}\right)\right]
\end{aligned}
$$

A modified model considering the angle between the direction of the entrainment velocity and the minor axis of the ellipse. In the EHL analysis of the tooth surface of the spiral bevel gear, the entrainment velocity of the meshing point is inconsistent with the minor-axis of the contact ellipse, and there is an included angle $\theta$ (Fig. 1). 


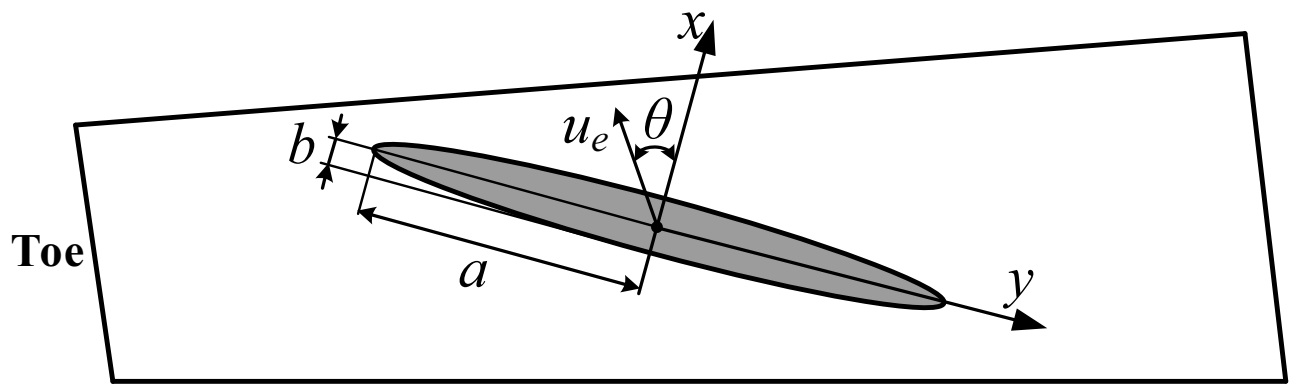

Root

Figure 1. Schematic diagram of the angle $\theta$ between the lubricant entrainment and the minor axis of the contact ellipse.

It is necessary to consider the influence of the angle on the distribution of the lubricating oil film. Pu proposed a modified model (considering the angle $\theta$ ), and the angle coefficient $\varepsilon$ is calculated as follows ${ }^{14}$ : (readers can refer to Ref. ${ }^{14}$ for more details.)

$$
\varepsilon=1+A_{1} \theta\left(1+B_{1}{\overline{U_{\mathrm{e}}}}^{i}+C_{1}{\overline{P_{\mathrm{h}}}}^{j}\right)+A_{2} \theta^{2}\left(1+B_{2}{\overline{U_{\mathrm{e}}}}^{m}+C_{2}{\overline{P_{\mathrm{h}}}}^{n}\right)+A_{3} \theta^{3}\left(1+B_{3}{\overline{U_{\mathrm{e}}}}^{r}+C_{3}{\overline{P_{\mathrm{h}}}}^{l}\right)+A_{4} \theta^{4}
$$

In the formula: $U_{e}=12.7 \times u_{e} \times \eta_{0} /\left(R_{x} E^{\prime}\right), P_{h}=p_{h} / E^{\prime}$.

The angle factor $\varepsilon$ is applied to L model to obtain Line-contact EHL considering the influence of $\theta$ (LA model). Similarly, the PA model can be obtained.

Line-contact EHL considering the influence of $\theta$ (LA model):

$$
\begin{aligned}
H_{\mathrm{c}} & =\varepsilon\left[2.691 W^{-0.135} U^{0.705} G^{0.556}\left(1+0.2 \bar{\sigma}^{1.222} V^{0.223} W^{-0.229} U^{-0.748} G^{-0.842}\right)\right] \\
H_{\min } & =\varepsilon\left[1.652 W^{-0.077} U^{0.716} G^{0.695}\left(1+0.026 \bar{\sigma}^{1.120} V^{0.185} W^{-0.312} U^{-0.809} G^{-0.977}\right)\right] \\
L_{a} & =0.005 W^{-0.408} U^{-0.088} G^{0.103}\left[\ln \left(1+4470 \bar{\sigma}^{6.015} V^{1.168} W^{0.485} U^{-3.741} G^{-2.898}\right)\right]
\end{aligned}
$$

Point-contact EHL considering the influence of $\theta$ (PA model):

$$
\begin{gathered}
H_{\mathrm{c}}=\varepsilon\left[3.672 W^{-0.045 \kappa^{0.18}} U^{0.663 \kappa^{0.025}} G^{0.502 \kappa^{0.064}}\left(1-0.573 e^{-0.74 \kappa}\right) \times\left(1+0.025 \bar{\sigma}^{1.248} V^{0.119} W^{-0.133} U^{-0.884} G^{-0.977} \kappa^{0.081}\right)\right] \\
H_{\min }=\varepsilon\left[1.637 W^{-0.09 \kappa^{-0.15}} U^{0.711 \kappa^{-0.023}} G^{0.65 \kappa^{-0.045}}\left(1-0.974 e^{-0.676 \kappa}\right)\right. \\
\left.\quad \times\left(1+0.141 \bar{\sigma}^{1.073} V^{0.149} W^{-0.044} U^{-0.828} G^{-0.945} \kappa^{-0.395}\right)\right]
\end{gathered}
$$

\section{Calculation of transient lubrication parameters of spiral bevel gears}

Lubrication analysis of the spiral bevel gear requires parameters of each meshing point: the combined curvature of the contact surface- $R_{x}, R_{y}$, the contact load at the contact point-F, the size and direction of the entrainment velocity- $\boldsymbol{v}^{\mathrm{e}}$.

The tooth contact force $F$ can be found through a loaded tooth contact analysis (LTCA) which can provide the contact force, contact path, transmission errors and bearing contact as a set of instantaneous contact ellipses ${ }^{33}$.

However, $\boldsymbol{v}^{\mathbf{e}}$ and $\theta$ need to be calculated based on the kinematics of the contact points on the tooth. The contact points on the pinion and gear are represented by a pinion surface position vector $\mathbf{r}^{\mathrm{p}}$ and a gear surface position vector $\mathbf{r}^{\mathrm{g}}$. The pinion surface velocity vector $\boldsymbol{v}^{\mathrm{p}}$ and the gear surface velocity vector $\boldsymbol{v}^{\mathrm{g}}$ are defined in Eqs. (13) and (14). $\omega^{\mathrm{p}}$ and $\omega^{\mathrm{g}}$ are the angular velocity vectors of the pinion and gear respectively. The entraining velocity vector $\boldsymbol{v}^{\mathbf{e}}$ is defined as per Eq. (16), and angle between the entraining velocity vector and the minor axis of the Hertzian ellipse $\theta$ can be derived from Eq. (17).

$$
\begin{gathered}
\boldsymbol{v}^{\mathrm{p}}=\omega^{\mathrm{p}} \times \mathbf{r}^{\mathrm{p}} \\
\boldsymbol{v}^{\mathrm{g}}=\omega^{\mathrm{g}} \times \mathbf{r}^{\mathrm{g}} \\
\boldsymbol{v}^{\mathrm{e}}=\frac{\boldsymbol{v}^{\mathrm{g}}+\boldsymbol{v}^{\mathrm{p}}}{2} \\
\boldsymbol{v}_{\mathrm{t}}^{\mathrm{e}}=\boldsymbol{v}^{\mathrm{e}}-\boldsymbol{v}^{\mathrm{e}} \cdot \mathbf{n} \cdot \mathbf{n}
\end{gathered}
$$




\begin{tabular}{|l|l|l|}
\hline & Pinion & Gear \\
\hline Number of teeth & 27 & 35 \\
\hline Module $(\mathrm{mm})$ & 5.27 & \multicolumn{2}{|l|}{} \\
\hline Outer pitch diameter $(\mathrm{mm})$ & 142.29 & 184.45 \\
\hline Face width $(\mathrm{mm})$ & 36.5 & \multicolumn{2}{|l|}{} \\
\hline Pitch angle $\left(^{\circ}\right)$ & $37^{\circ} 39^{\prime}$ & $52^{\circ} 21^{\prime}$ \\
\hline Face angle $\left(^{\circ}\right)$ & $40^{\circ} 7^{\prime}$ & $54^{\circ} 38^{\prime}$ \\
\hline Root angle $\left(^{\circ}\right)$ & $35^{\circ} 22^{\prime}$ & $49^{\circ} 15^{\prime}$ \\
\hline Outer cone distance $(\mathrm{mm})$ & 116.48 & \\
\hline Pressure angle at normal section $\left(^{\circ}\right)$ & 20 & \\
\hline Mean helix angle $\left(^{\circ}\right)$ & 40 & \multicolumn{2}{|l|}{} \\
\hline Shaft angle $\left(^{\circ}\right)$ & 90 & Right hand \\
\hline Hand of spiral & Left hand & 4 \\
\hline ISO quality grade & 4 & Grinding \\
\hline Precision machining & Grinding & 18 CrNi4WA \\
\hline Material & 18 CrNi4WA & HRC60 \\
\hline Surface hardness & HRC60 & Ra0.4 \\
\hline Surface roughness $(\mu m)$ & Ra0.4 & \\
\hline Rotating speed(rpm) & 6000 & 339 \\
\hline Torque(Nm) & \multicolumn{2}{|l}{} \\
\hline
\end{tabular}

Table 2. Geometry and working parameters of the example of spiral bevel gear pair.

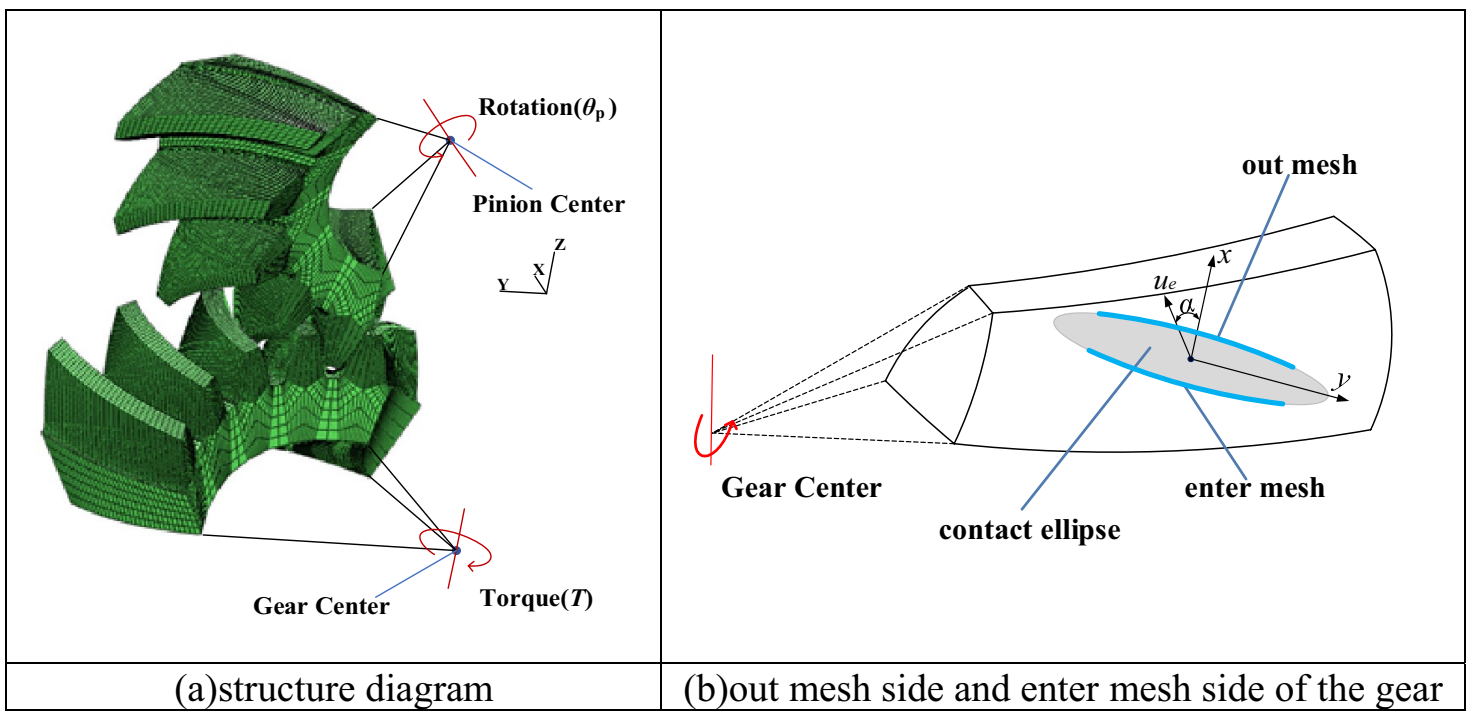

Figure 2. Structure diagram of spiral bevel gears.

$$
\begin{gathered}
\cos \theta=\frac{\boldsymbol{v}_{\mathrm{t}}^{\mathrm{e}} \cdot \mathbf{b}}{\left|\boldsymbol{v}_{\mathrm{t}}^{\mathrm{e}}\right||\mathbf{b}|} \\
p_{h}=\frac{3 F}{2 \pi a b}
\end{gathered}
$$

Taking helicopter main transmission spiral bevel gears as an example, geometry parameters and the operating conditions of the spiral bevel gears are specified in Table 2. The structure diagram of the spiral bevel gears is shown in Fig. 2.

The main material parameters and lubricating oil characteristics of spiral bevel gears are summarized in Table 3 .

Based on the results of LTCA, the contact parameters of the lubrication analysis of the spiral bevel gear are calculated. Table 4 shows the contact curvature, load and lubricant entraining velocity at different contact positions. 


\begin{tabular}{|l|l|}
\hline Young's modulus of body, $E_{1}, E_{2}(\mathrm{~Pa})$ & $2.11 \times 10^{11}$ \\
\hline Poisson's ratio of body, $v_{1}, v_{2}$ & 0.3 \\
\hline Surface roughness, $\sigma_{1}, \sigma_{2}(\mathrm{~m})$ & $4 \times 10^{-7}$ \\
\hline Vickers hardness $h d_{1}, h d_{2}(\mathrm{HV})$ & 697.5 \\
\hline Lubricant viscosity, $\eta_{0}(\mathrm{~Pa} . \mathrm{s})$ & 0.04 \\
\hline Pressure viscosity coefficient, $\alpha\left(\mathrm{Pa}^{-1}\right)$ & $2.2 \times 10^{-8}$ \\
\hline
\end{tabular}

Table 3. Material parameters and lubricating oil characteristics of spiral bevel gears.

\begin{tabular}{|l|l|l|l|l|l|l|c|}
\hline $\boldsymbol{N}$ & $\boldsymbol{\theta}_{\mathrm{p}}\left(^{\circ}\right)$ & $\boldsymbol{R}_{\boldsymbol{x}}(\mathbf{m m})$ & $\boldsymbol{R}_{\boldsymbol{y}}(\mathbf{m m})$ & $\boldsymbol{F}(\mathrm{N})$ & $\boldsymbol{u}_{\mathrm{e}}(\mathbf{m} / \mathbf{s})$ & $\boldsymbol{\theta}\left(^{\circ}\right)$ & $\boldsymbol{p}_{\boldsymbol{h}}(\mathbf{M P a})$ \\
\hline 1 & -10.285 & 12.61 & 770.79 & 211.91 & 27.61 & 55.81 & 613.44 \\
\hline 2 & -9.2568 & 12.58 & 779.57 & 789.49 & 27.15 & 55.80 & 795.33 \\
\hline 3 & -8.2282 & 12.55 & 788.57 & 1393.5 & 26.70 & 55.75 & 967.30 \\
\hline 4 & -7.1996 & 12.51 & 797.85 & 2224.4 & 26.25 & 55.70 & 1137.98 \\
\hline 5 & -6.171 & 12.47 & 807.40 & 3088.7 & 25.79 & 55.65 & 1274.41 \\
\hline 6 & -5.1424 & 12.42 & 817.26 & 3994.1 & 25.34 & 55.59 & 1392.18 \\
\hline 7 & -4.1138 & 12.37 & 827.43 & 4902.2 & 24.88 & 55.53 & 1493.86 \\
\hline 8 & -3.0852 & 12.32 & 837.93 & 5775.2 & 24.43 & 55.47 & 1580.82 \\
\hline 9 & -2.0566 & 12.25 & 848.79 & 6582.1 & 23.98 & 55.42 & 1654.30 \\
\hline 10 & -1.028 & 12.19 & 860.03 & 7251.8 & 23.53 & 55.36 & 1711.40 \\
\hline 11 & 0 & 12.12 & 871.63 & 7636.6 & 23.07 & 55.31 & 1743.03 \\
\hline 12 & 1.0286 & 12.04 & 883.67 & 7095.7 & 22.62 & 55.24 & 1699.10 \\
\hline 13 & 2.0609 & 11.96 & 896.09 & 6504.7 & 22.17 & 55.18 & 1648.83 \\
\hline 14 & 3.0893 & 11.88 & 909.10 & 5679.8 & 21.72 & 55.12 & 1573.63 \\
\hline 15 & 4.1179 & 11.78 & 922.61 & 4817.8 & 21.27 & 55.06 & 1487.42 \\
\hline 16 & 5.1466 & 11.69 & 936.74 & 3909.9 & 20.83 & 55.01 & 1385.14 \\
\hline 17 & 6.1751 & 11.58 & 951.46 & 2996.1 & 20.38 & 54.95 & 1264.95 \\
\hline 18 & 7.2039 & 11.47 & 966.83 & 2115.2 & 19.93 & 54.90 & 1122.97 \\
\hline 19 & 8.2323 & 11.36 & 982.90 & 1300.0 & 19.49 & 54.85 & 949.64 \\
\hline 20 & 9.2609 & 11.24 & 999.69 & 625.55 & 19.04 & 54.80 & 739.04 \\
\hline 21 & 10.29 & 11.11 & 1017.36 & 22.818 & 18.60 & 54.70 & 96.77 \\
\hline & & & & & & & \\
\hline
\end{tabular}

Table 4. Spiral bevel gear's contact parameters of the meshing point.

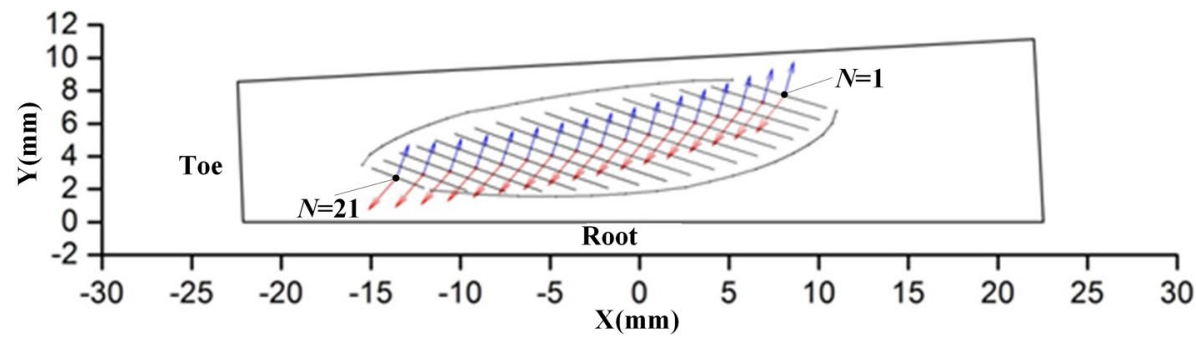

Figure 3. The lubricant entraining velocity and the minor axis of the contact ellipse of the different meshing positions of the gears.

According to the contact parameters of Table 4, the lubricant entraining velocity $\mathbf{v}^{\mathbf{e}}$ and the minor axis of the contact ellipse are obtained, as shown in Fig. 3. (The blue arrows are the direction of the minor axis of the ellipse, and red arrows are the direction of the entrainment velocity vector, respectively.)

The changes of the contact load $F$, entraining velocity $\boldsymbol{v}^{\mathbf{e}}$ and angle $\theta$ are shown in Fig. 4. The driven gear tooth surface enters the mesh from the tooth tip near the large end side, and is engaged from the tooth root near the small end side. Compare the different engagement positions, the entraining velocity at addendum (enter mesh) is maximal, and the entrainment at the root position (out mesh) is minimal. As the meshing position moves from the addendum to the root, the angle between the lubricant entraining velocity and the minor axis of the contact ellipse becomes small. 


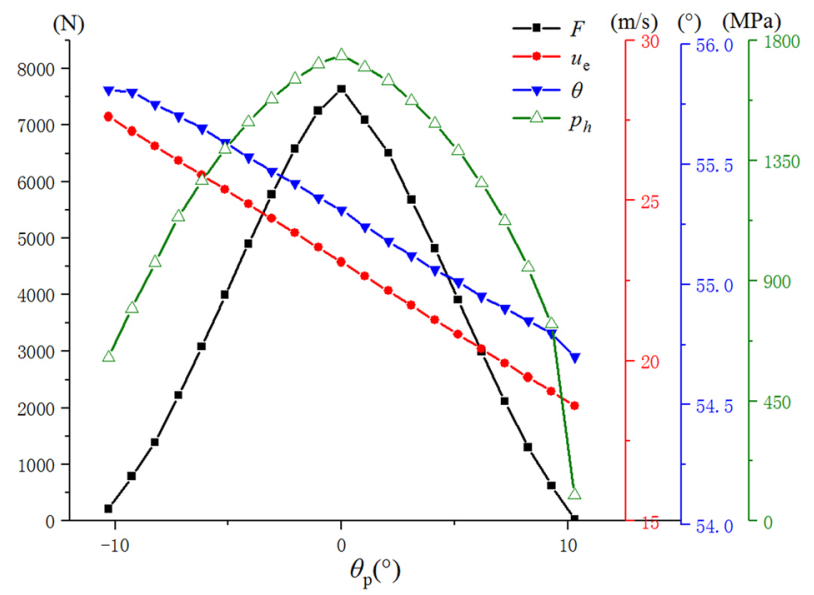

Figure 4. Contact load, lubricant entraining velocity and angle changing with the meshing position.

Figure 4 shows the meshing process, the contact force changes from 22.8 to $7636.6 \mathrm{~N}$, the variation range being close to $100 \%$ and the maximum force appears in the contact center; the entrainment velocity changes from 18.6 to $27.6 \mathrm{~m} / \mathrm{s}$, the variation range reaches $32.6 \%$ and the maximum speed appears at the beginning of mesh; the angle $\theta$ changes from $54.7^{\circ}$ to $55.8^{\circ}$, with a small variation (only $2 \%$ ). This is due to the small change of tooth surface radian in the meshing process.

\section{Point contact numerical model and oil film thickness calculation}

Based on the numerical calculation method of the circular contact EHL model provided by Venner ${ }^{34}$ (Moreover, this model had been validated well agreed with relevant friction experiments and readers can refer to research ${ }^{35}$ for more details.), the coordinate transformation method is used in the oil film distribution equation, and the angle between the entraining velocity and the minor axis of Hertzian ellipse is considered. This makes it suitable for the analysis of the lubrication characteristics of spiral bevel gears.

Numerical solution method of lubrication equation. Using the coordinate transformation in the oil film thickness equation, the angle $\theta$ is placed in the calculation formula, and the Reynolds equation is:

$$
\frac{\partial}{\partial x}\left(\frac{\rho h^{3}}{12 \eta} \frac{\partial p}{\partial x}\right)+\frac{\partial}{\partial y}\left(\frac{\rho h^{3}}{12 \eta} \frac{\partial p}{\partial y}\right)=u_{e} \cos \theta \frac{\partial(\rho h)}{\partial x}+u_{e} \sin \theta \frac{\partial(\rho h)}{\partial y}+\frac{\partial(\rho h)}{\partial t}
$$

After considering the angle $\theta$, the Reynolds equation of the film thickness is unchanged, and the oil film thickness equation ${ }^{34}$ becomes:

$$
h=h_{0}+\frac{(x \cos \theta-y \sin \theta)^{2}}{2 R_{x}}+\frac{(x \sin \theta+y \cos \theta)^{2}}{2 R_{y}}+\frac{1+R_{x} / R_{y}}{2 \pi \varepsilon_{1}} \iint_{\Omega} \frac{p\left(x^{\prime}, y^{\prime}\right)}{\sqrt{\left(x-x^{\prime}\right)^{2}+\left(y-y^{\prime}\right)^{2}}} d x^{\prime} d y^{\prime}+\sigma_{1}(x, y)+\sigma_{2}(x, y)
$$

where $h_{0}$ is a function of time and denotes the normal approach of the two rigid body surfaces, $(x \cos \theta-y \sin \theta)^{2} / 2 R_{\mathrm{x}}$ and $(x \sin \theta-y \cos \theta)^{2} / 2 R_{\mathrm{y}}$ are the transient geometry before elastic deformation, $\varepsilon_{1}=\int_{0}^{\pi / 2} \sqrt{1-\left(1-\kappa^{2}\right) \sin ^{2} \xi} \mathrm{d} \xi$, $\kappa=a / b, \Omega$ indicates the entire solution area. The solution area: $-4.5 \mathrm{a} \leq \mathrm{x} \leq 1.5 \mathrm{a},-3.0 \mathrm{~b} \leq \mathrm{y} \leq 3.0 \mathrm{~b}$. (Material parameters and lubricating oil characteristics $E, v, \sigma_{1}, \sigma_{2}, h d, \eta_{0}, \alpha$ are enclosed in Table 3 , contact parameter $R_{x}, R_{y}, \theta$, $u_{\mathrm{e}}$ are enclosed in Table 4.)

The method of changing the oil film thickness equation transforms the initial position of the contact surface so that the minor axis of Hertzian ellipse rotates along the coordinate system of the Reynolds equation.

Analysis of transient lubrication performance of spiral bevel gear based on point contact numerical model. According to the contact parameters of spiral bevel gear in Table 4, the point contact EHL model is used to analyze each contact point. Figure 5 shows oil film thickness of the meshing intermediate position $(N=11)$ is the smallest, $0.2 \mu \mathrm{m}$. While the oil film thickness at the enter mesh side $(N=1)$ and the out mesh side $(N=21)$ is larger, reaching $1.4 \mu \mathrm{m}$. During the meshing process of the spiral bevel gear, the change of the size and direction of the entrainment velocity of different contact points is small, but the load change of the contact point is obvious. This indicates that the contact point load is the main factor affecting the oil film thickness in the contact area.

A comparison of the oil film thickness at the enter mesh side and the out mesh side (Fig. 5) shows that the oil film thickness at the out mesh side is smaller than that at the enter mesh side in the case where the contact force is equal. 


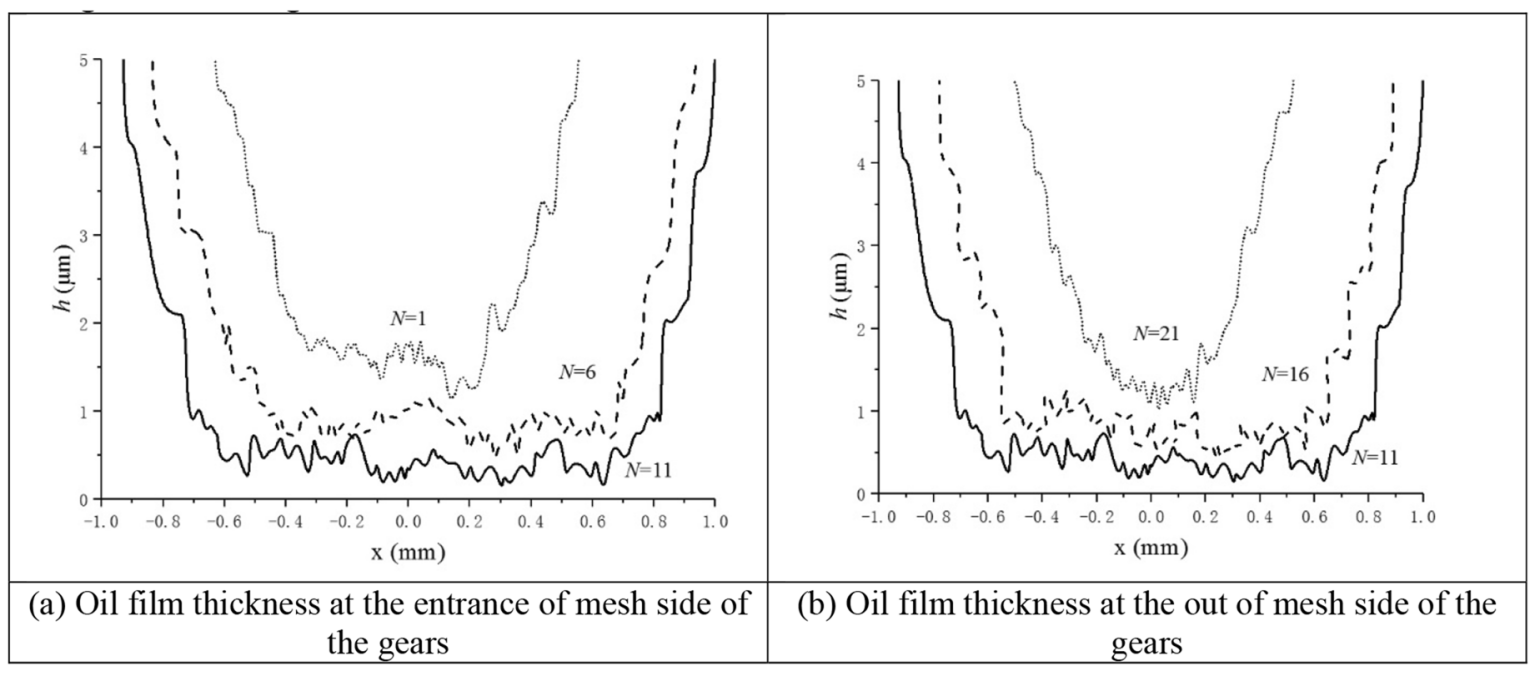

Figure 5. Oil film thickness distribution at different contact points.

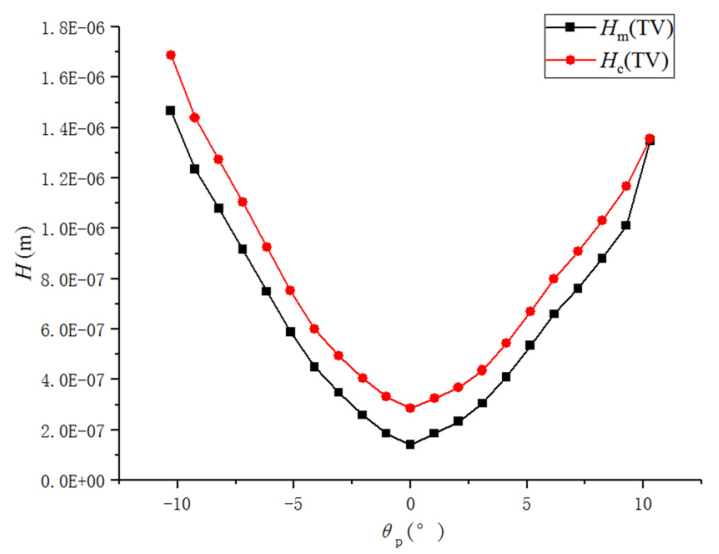

Figure 6. Oil film thickness at each mesh point calculated by the point contact numerical model.

The oil film thickness of the driven gear at the root is smaller than that at the top of the driven gear. This results from both the decrease of the lubricant entraining velocity and the decrease of the entrainment angle $\theta$ at the out mesh side. It also shows that tooth surface roughness has a great influence on the distribution of oil film center.

The oil film thickness distribution at each contact point of the gear is shown in Fig. 6. During the gear meshing process, the distribution of oil film thickness at each contact point is clearly consistent with the load change trend. (light load- heavy load- light load). Under light load, the contact area is narrow, the thickness of the oil film is relatively large, and the oil film thickness at the out mesh side is significantly contracted. Under heavy load, the contact area is widened with the Hertz contact deformation occurring on the tooth surface, the oil film distribution in the contact area is relatively uniform, and the necking phenomenon at the out mesh side of oil film thickness still exists.

\section{Compare lubrication characteristics of different models}

In the numerical solution of the point contact EHL model, the boundary conditions and initial values need to be changed with the contact parameters. In the analysis of the spiral bevel gear lubrication, the parameters of the contact point constantly change with the meshing position. It is necessary to amend the calculation parameters continuously to obtain the oil film thickness and pressure distribution, which will take considerable time. In this section, the simplified model of gear lubrication is used to analyze the lubrication of spiral bevel gears, and the calculation results of different models are compared.

Comparison of lubrication analysis results of different simplified models. For contact lubrication of spiral bevel gears, the contact area ellipse is relatively large. Researchers ${ }^{36}$ believe that it is closer to line contact and can be solved using a line contact model. In order to compare the applicability of different models in the analysis of spiral bevel gear lubrication, the central film thickness $\left(h_{\mathrm{c}}\right)$ and minimum film thickness $\left(h_{\min }\right)$ calculated by different models are shown in Fig. 7. 


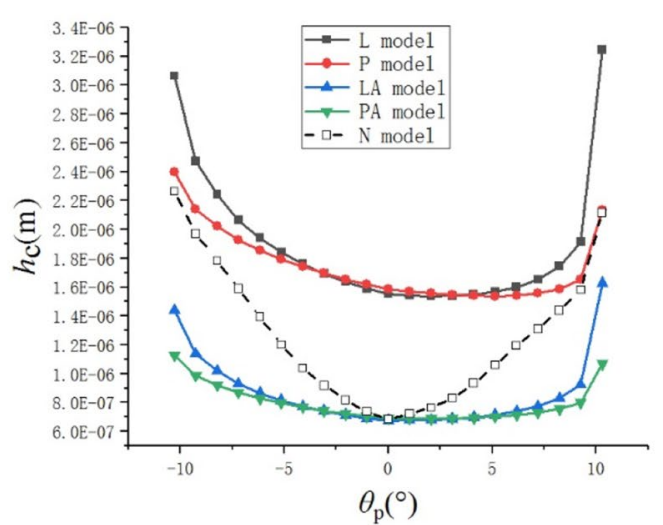

(a)Central film thickness of different calculation models

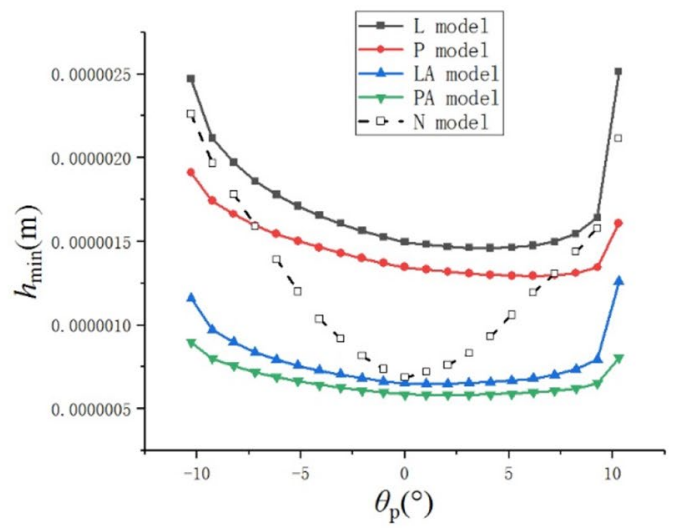

(b)Minimum film thickness of different calculation models

Figure 7. Central oil film thickness and minimum oil film thickness for different calculation models.

\begin{tabular}{|l|l|l|}
\hline & $\boldsymbol{h}_{\min }(\mathbf{m})$ & $\boldsymbol{h}_{\mathbf{c}}(\mathbf{m})$ \\
\hline P model & $5.02 \times 10^{-7}$ & $6.53 \times 10^{-7}$ \\
\hline L model & $1.70 \times 10^{-6}$ & $1.89 \times 10^{-6}$ \\
\hline PA model & $6.58 \times 10^{-7}$ & $7.95 \times 10^{-7}$ \\
\hline LA model & $7.77 \times 10^{-7}$ & $8.65 \times 10^{-7}$ \\
\hline
\end{tabular}

Table 5. Comparison of calculation results of different models with numerical simulation results.

\begin{tabular}{|l|l|l|}
\hline$N_{\mathrm{w}}$ & $\boldsymbol{P}_{\mathrm{w}}(\mathbf{k W})$ & $\boldsymbol{T}(\mathbf{N m})(\mathbf{6 0 0 0} \mathbf{r} / \mathbf{m i n})$ \\
\hline 1 & 213 & 339 \\
\hline 2 & 378 & 602 \\
\hline 3 & 450 & 716 \\
\hline
\end{tabular}

Table 6. working load of the spiral bevel gear.

It can be seen that the oil film thickness calculated by the PA model is close to that of LA model, and the calculation result of the PA model is smaller. The difference between the calculation results is whether the correction coefficient $(\varepsilon)$ of the angle is considered or not. In this example, the correction coefficient $\varepsilon$ of each meshing position is about 0.43 to 0.5 . The calculation result of the correction coefficient $\varepsilon$ is consistent with the calculation result ${ }^{37}$ of "effect of arbitrary entrainment angle in elastohydrodynamic lubrication elliptical and circular contacts".

In Fig. 7, the changing trends of line and point contact formulae are similar in the middle position and different in both sides. It is because that film thickness is very little influenced by load (in Eq. (1): -0.135 exponent) and very much influenced by entrainment velocity (in Eq. (1): 0.705 exponent).

Using different formulae to calculate oil film thickness, the main difference is the calculation of force. $W=F /\left(B E^{\prime} R\right)$ in line contact and $W=F /\left(E^{\prime} R^{2}\right)$ in point contact. $(B=2 b$, choose long semi-axis length of Hertz contact ellipse to calculate contact length, the change of $b$ is very small.) Although the force changes greatly, from 22 to $7636 \mathrm{~N}$, the influence of force in the formula is small. Only when the force approaches 0 in both sides $(22 / 7636 \approx 0)$, film thickness of different formulae will be different.

Using L model to calculate film thickness of the spiral bevel gears will cause a large calculation error (Fig. 7). By comparing the calculation results of different simplified models and point contact lubrication numerical model (Table 5): it can be found that the calculation of the minimum film thickness by LA model is more accurate, and the prediction of the change tendency of the film thickness is more accurate. In conclusion, LA model is the closest model to the simulation results of the point contact numerical model ( $\mathrm{N}$ model). For the lubrication analysis of spiral bevel gears, it is recommended to use the LA model rather than L model.

Effect of working load on oil film thickness of spiral bevel gear. The load change in the tooth surface of the spiral bevel gear affects the contact area parameters. The gears in Table 4 are taken as an example, three working conditions in Table 6 are selected to analyze the effect of load on the oil film thickness at each contact point of the spiral bevel gear. 


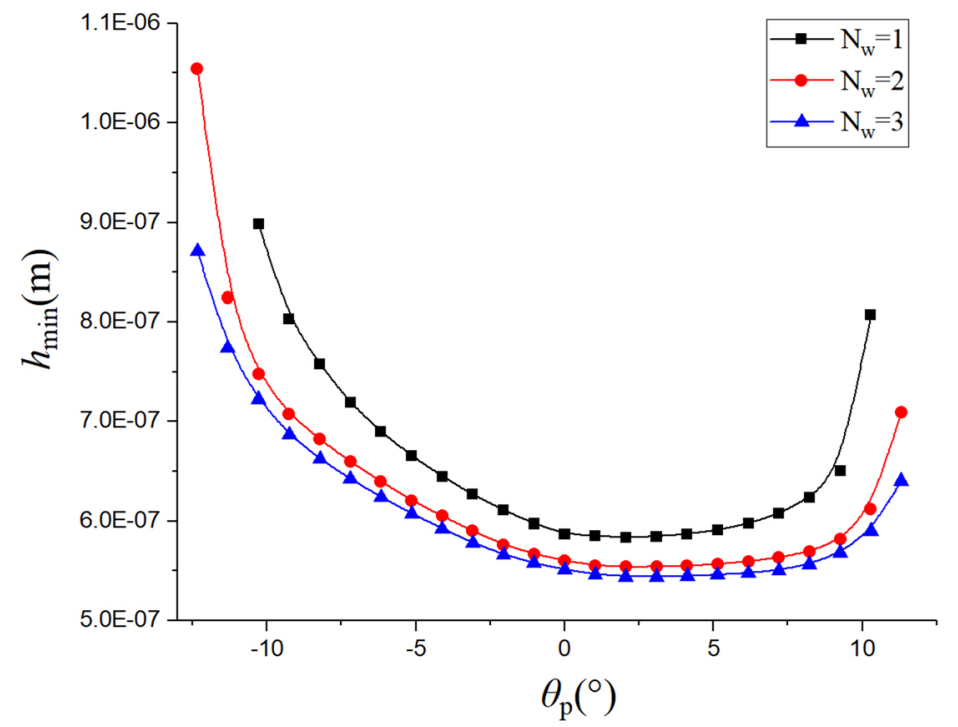

Figure 8. Oil film thickness under different working conditions.

In the simplified point contact model, the variations of the oil film thickness on the tooth surface under different working conditions are compared (Fig. 8). It can be seen that film thickness of the tooth surface decreases as the gear torque load increases. As the load increases, the contact area of the tooth surface becomes larger, and the range of the rotational angle of the gear also increases.

\section{Conclusion}

In this paper, an engineering calculation model is introduced for point-contact EHL analysis of spiral bevel gears. Through numerical solution, the point contact EHL analysis under different loads and entraining velocity directions is performed. Using different simplified models and numerical models to calculate the oil film thickness and change trend of helicopter spiral bevel gears. The conclusions drawn from the present study include:

1. The instantaneous contact area of the spiral bevel gear is a long and narrow ellipse, and the influence of $\theta$ (the angle between the lubricant entraining velocity and the minor axis of the contact ellipse) should be considered in the EHL analysis of the spiral bevel gear.

2. During gear meshing process, the contact force $F$ change range is close to $100 \%$, contact force first increases and then decreases; the entrainment velocity $\mathbf{v}^{\mathbf{e}}$ reduced by $32.6 \%$; the angle $\theta$ reduced by $2 \%$. Due to the decrease of $\mathbf{v}^{\mathbf{e}}$ and angle $\theta$, the film thickness at the out mesh side is smaller than that at the enter mesh side under the same contact force.

3. When the contact load is small, the contact area will be narrow, the film thickness will be relatively large, the film thickness will have a noticeable shrink at the out mesh side of the spiral bevel gears. When the contact load is high, the Hertz contact deformation will be evident, which leads to the enlargement of the contact area, the film thickness will be reduced and the distribution will become uniform.

4. The LA model is recommended for helicopter main transmission spiral bevel gears lubrication analysis, and the calculation result of the LA model is closer to that of the theoretical model. However, the simplified model's film thickness distribution form is relatively gradual during the meshing process.

5. For helicopter main transmission spiral bevel gears, it is recommended that the tooth surface roughness reach $\mathrm{Ra} 0.4$ or better. The tooth surface roughness has a great influence on the distribution of oil film in the center. The stability of lubricating oil film can be effectively improved by reducing the surface roughness, especially the roughness on the meshing trace line. When the input condition of spiral bevel gears is determined, increasing the contact area of tooth surface can directly reduce the contact stress, increase film thickness and improve the lubrication stability.

\section{Appendix}

Notation.

\begin{tabular}{|l|l|}
\hline $\mathrm{a}$ & Semi-axis of the Hertzian contact ellipse in the $\mathrm{x}$-direction, $\mathrm{m}$ \\
\hline $\mathrm{b}$ & Semi-axis of the Hertzian contact ellipse in the y-direction, $\mathrm{m}$ \\
\hline $\mathrm{E}_{1}, \mathrm{E}_{2}$ & Young's modulus of pinion and gear, respectively \\
\hline$v_{1}, v_{2}$ & Poisson's ratios of pinion and gear, respectively \\
\hline$E^{\prime}$ & Effective Young's modulus, $1 / E^{\prime}=0.5\left[\left(1-v_{1}^{2}\right) / E_{1}+\left(1-v_{2}^{2}\right) / E_{2}\right]$ \\
\hline $\mathrm{h}$ & Film thickness, $\mathrm{m}$ \\
\hline
\end{tabular}




\begin{tabular}{|c|c|}
\hline$h_{\mathrm{c}}$ & Central film thickness, $\mathrm{m}$ \\
\hline $\mathrm{h}_{\min }$ & Minimum film thickness, $\mathrm{m}$ \\
\hline $\mathrm{H}$ & Dimensionless film thickness, $\mathrm{H}=\mathrm{h} / \mathrm{R}$ \\
\hline $\mathrm{H}_{\mathrm{c}}$ & Dimensionless central film thickness, $H_{c}=h_{c} / R$ \\
\hline $\mathrm{H}_{\min }$ & Dimensionless minimum film thickness, $\mathrm{H}_{\min }=\mathrm{h}_{\min } / \mathrm{R}$ \\
\hline$L_{a}$ & Asperity load ratio (percentage) \\
\hline $\mathrm{x}$ & $\mathrm{x}$-coordinate, $\mathrm{m}$ \\
\hline $\mathrm{y}$ & $\mathrm{y}$-coordinate, $\mathrm{m}$ \\
\hline $\mathrm{R}_{\mathrm{x}}$ & Effective radius in the $\mathrm{x}$-direction, $\mathrm{m}$ \\
\hline $\mathrm{R}_{\mathrm{y}}$ & Effective radius in the $\mathrm{y}$-direction, $\mathrm{m}$ \\
\hline $\mathrm{R}$ & Equivalent contact radius, $1 / \mathrm{R}=(\cos \theta)^{2} / \mathrm{R}_{\mathrm{x}}+(\sin \theta)^{2} / \mathrm{R}_{\mathrm{p}} \mathrm{m}$ \\
\hline$\sigma$ & Surface roughness, standard deviation of the surface heights, $\mathrm{m}$ \\
\hline $\bar{\sigma}$ & Dimensionless surface roughness, $\bar{\sigma}=\sigma / R$ \\
\hline F & Contact force at the contact point, $\mathrm{N}$ \\
\hline B & Contact length, $\mathrm{m}$ \\
\hline $\mathrm{W}$ & $\begin{array}{l}\text { Dimensionless load parameter, } W=F /\left(B E^{\prime} R\right) \text { in line contact and } \\
W=F /\left(E^{\prime} R^{2}\right) \text { in point contact }\end{array}$ \\
\hline G & Dimensionless material number, $\mathrm{G}=E^{\prime} \alpha$ \\
\hline hd & Vickers hardness, $\mathrm{Pa}$ \\
\hline V & Dimensionless hardness number, $V=h d / E^{\prime}$ \\
\hline$\eta$ & Lubricant viscosity, Pa.s \\
\hline$\eta_{0}$ & Lubricant viscosity at atmospheric pressure, Pa.s \\
\hline $\mathrm{U}$ & Dimensionless speed number, $U=\left(\eta_{0} u_{e}\right) /\left(E^{\prime} R\right)$ \\
\hline$\kappa$ & Hertzian contact ellipticity, $\kappa=a / b$ \\
\hline$\theta$ & $\begin{array}{l}\text { angle between the entraining velocity vector and the minor axis of Hertzian } \\
\text { ellipse }\end{array}$ \\
\hline$\varepsilon$ & Correction factor, represents the influence of $\theta$ \\
\hline $\mathrm{P}$ & Dimensionless parameter of pressure, $P=p / p_{h}$ \\
\hline $\bar{\lambda}$ & $\bar{\lambda}=\left(12 \eta_{0} u_{e} R_{x}^{2}\right) /\left(b^{3} p_{h}\right)$ \\
\hline$\rho_{0}$ & Lubricating oil density at normal atmospheric pressure \\
\hline $\mathrm{N}$ & Number of the contact position \\
\hline$\theta_{\mathrm{p}}$ & Rotation angle of gear \\
\hline$p_{h}(\mathrm{GPa})$ & Maximum Hertz contact stress, $p_{h}=(3 F) /(2 \pi a b)$ \\
\hline$\alpha\left(\mathrm{Pa}^{-1}\right)$ & Pressure viscosity coefficient, $\alpha=2.2 \times 10^{-8} \mathrm{~Pa}^{-1}$ \\
\hline $\mathbf{r}^{\mathrm{P}}$ & Pinion surface position vector \\
\hline $\mathbf{r}^{\mathrm{g}}$ & Gear surface position vector \\
\hline$\omega^{\mathrm{p}}$ & The angular velocity vectors of the pinion \\
\hline$\omega^{\mathrm{g}}$ & The angular velocity vectors of the gear \\
\hline$v^{\mathrm{P}}$ & Pinion surface velocity vector \\
\hline $\boldsymbol{v}^{\mathrm{g}}$ & Gear surface velocity vector \\
\hline$v^{\mathrm{e}}$ & Entraining velocity vector \\
\hline$v_{\mathrm{t}}^{\mathrm{e}}$ & $v^{\mathrm{e}}$ projection on the tangent plane \\
\hline$u_{e}$ & Entraining velocity, $u_{e}=\left|\mathbf{v}_{\mathrm{t}}^{\mathrm{e}}\right|, \mathrm{m} / \mathrm{s}$ \\
\hline P model & Point-contact EHL \\
\hline L model & Line-contact EHL \\
\hline PA model & Point-contact EHL considering the influence of $\theta$ \\
\hline LA model & Line-contact EHL considering the influence of $\theta$ \\
\hline $\mathrm{N}$ model & Point contact numerical model \\
\hline $\mathrm{N}_{\mathrm{w}}$ & Working condition number \\
\hline $\mathrm{P}_{\mathrm{w}}$ & Input power, $\mathrm{kW}$ \\
\hline $\mathrm{T}$ & Input torque, $\mathrm{Nm}$ \\
\hline
\end{tabular}

Received: 18 February 2020; Accepted: 8 October 2021

Published online: 22 October 2021

\section{References}

1. Christensen, H. \& Tonder, K. The hydrodynamic lubrication of rough bearing surfaces of finite width. J. Lubr. Technol. 3, 324-329 (1971). 
2. Patir, N. \& Cheng, H. S. Application of average flow model to lubrication between rough sliding surfaces. J. Lubr. Technol. Trans. ASME. 101, 220-230 (1979).

3. Chang, L. \& Webster, M. N. A study of elastohydrodynamic lubrication of rough surfaces. J. Tribol. 1, 110-115 (1991).

4. Chang, L., Jackson, A. \& Webster, M. N. A study of asperity interactions in Ehl line contacts. Tribol. T. 36, 4 (1993).

5. Venner, C. H. \& Napel, W. E. Surface roughness effects in an Ehl line contact. J. Tribol. 114, 616-622 (1992).

6. Venner, C. H. \& Lubrecht, A. A. Transient analysis of surface features in an Ehl line contact in the case of sliding. J. Tribol. 116, 186-193 (1994).

7. Ai, X., Cheng, H. S. \& Zheng, L. Transient model for micro-elastohydrodynamic lubrication with three-dimensional irregularities. J. Tribol. 115, 102-110 (1993).

8. Ai, X. Numerical Analyses of Elastohydrodynamically Lubricated Line and Point Contacts with Rough Surfaces by Using Semi-System and Multigrid Methods (ProQuest LLC, 1993).

9. Evans, H. P. \& Snidle, R. W. Inverse solution of Reynolds' equation of lubrication under point-contact elastohydrodynamic conditions. J. Lubr. Technol. 103, 539-546 (1981).

10. Evans, H. P. \& Snidle, R. W. Analysis of micro-elastohydrodynamic lubrication for engineering contacts. Tribol. Int. 29, 659-667 (1996).

11. Evans, H. P., Snidle, R. W. \& Sharif, K. J. Deterministic mixed lubrication modelling using roughness measurements in gear applications. Tribol. Int. 42, 1406-1417 (2009).

12. Simon, V. Influence of machine tool setting parameters on Ehd lubrication in hypoid gears. Mech. Mach. Theory 44, 923-937 (2009).

13. Simon, V. V. Improvements in the mixed elastohydrodynamic lubrication and in the efficiency of hypoid gears. Proc. Inst. Mech. Eng. Part J J. Eng. Tribol. 234, 795-810 (2020).

14. Pu, W., Wang, J., Zhang, Y. \& Zhu, D. A Theoretical analysis of the mixed elastohydrodynamic lubrication in elliptical contacts with an arbitrary entrainment angle. J. Tribol.-T. Asme. 136, 1-11 (2014).

15. Pu, W., Wang, J., Zhou, G., Xiao, K. \& Li, J. Effect of surface topography associated with arbitrary velocity direction on the lubrication film thickness in elliptical contacts. Ind. Lubr. Tribol. 70, 444-452 (2018).

16. Wang, Z., Pu, W., He, T., Wang, J. \& Cao, W. Numerical simulation of transient mixed elastohydrodynamic lubrication for spiral bevel gears. Tribol. Int. 139, 67-77 (2019).

17. Wang, Z., Pu, W., Zhang, Y. \& Cao, W. Transient behaviors of friction, temperature and fatigue in different contact trajectories for spiral bevel gears. Tribol. Int. 141, 105965 (2020).

18. Pei, X., Huang, L., Pu, W. \& Wei, P. Dynamical wear prediction along meshing path in mixed lubrication of spiral bevel gears. $A d v$. Mech. Eng. 12, 2072264911 (2020).

19. Pei, X., Pu, W. \& Wang, Z. Contact stiffness and dynamic behavior caused by surface defects of spiral bevel gear in mixed lubrication. Eng. Fail. Anal. 121, 105129 (2021).

20. Cheng, Y. \& Lim, T. C. Vibration analysis of hypoid transmissions applying an exact geometry-based gear mesh theory. J. Sound Vib. 240, 519-543 (2001).

21. Cheng, Y. P. \& Lim, T. C. Dynamics of hypoid gear transmission with nonlinear time-varying mesh characteristics. J. Mech. Design. 125, 373-382 (2003).

22. Lim, T. C. \& Wang, J. Effects of assembly errors on hypoid gear mesh and dynamic response. In Proceedings of the ASME International Design Engineering Technical Conferences and Computers and Information in Engineering Conference. Long Beach, CA 801-806 (2005).

23. Alves, J. T., Wang, J., Guingand, M., de Vaujany, J. \& Velex, P. Static and dynamic models for spiral bevel gears. Mech. Ind. 13, 325-335 (2012).

24. Barbieri, M., Lubrecht, A. A. \& Pellicano, F. Behavior of lubricant fluid film in gears under dynamic conditions. Tribol. Int. 62, 37-48 (2013).

25. Xue, J., Li, W. \& Qin, C. The scuffing load capacity of involute spur gear systems based on dynamic loads and transient thermal elastohydrodynamic lubrication. Tribol. Int. 79, 74-83 (2014).

26. Cao, W., Pu, W., Wang, J. \& Xiao, K. Effect of contact path on the mixed lubrication performance, friction and contact fatigue in spiral bevel gears. Tribol. Int. 123, 359-371 (2018).

27. Cao, W., Pu, W. \& Wang, J. Tribo-dynamic model and fatigue life analysis of spiral bevel gears. Eur. J. Mech. A Solids 74, 124-138 (2019).

28. Gan, L., Xiao, K., Wang, J., Pu, W. \& Cao, W. A numerical method to investigate the temperature behavior of spiral bevel gears under mixed lubrication condition. Appl. Therm. Eng. 147, 866-875 (2019).

29. Sun, X., Liu, Y., Zhao, Y. \& Liu, M. Ehl analysis of spiral bevel gear pairs considering the contact point migration due to deformation under load. Math. Probl. Eng. 2020, 1-19 (2020).

30. Dowson, D. \& Toyoda, S. A central film thickness formula for elastohydrodynamic line contacts. In Proceedings of the 5th LeedsLyon Symposium on Tribology (1978).

31. Masjedi, M. \& Khonsari, M. M. Film thickness and asperity load formulas for line-contact elastohydrodynamic lubrication with provision for surface roughness. J. Tribol. 134, 1-10 (2012).

32. Masjedi, M. \& Khonsari, M. M. An engineering approach for rapid evaluation of traction coefficient and wear in mixed Ehl. Tribol. Int. 92, 184-190 (2015).

33. Litvin, F. \& Fuentes, A. Gear Geometry and Applied Theory (Cambridge University Press, 2004).

34. Venner, C. \& Lubrecht, A. Multi-level Methods in Lubrication (Elsevier, 2000).

35. Pu, W., Wang, J. \& Zhu, D. Friction and flash temperature prediction of mixed lubrication in elliptical contacts with arbitrary velocity vector. Tribol. Int. 99, 38-46 (2016).

36. Bobach, L., Beilicke, R. \& Bartel, D. Transient thermal elastohydrodynamic simulation of a spiral bevel gear pair with an octoidal tooth profile under mixed friction conditions. Tribol. Int. 106020, 1-13 (2020).

37. Kumar, P. K. P. Effect of arbitrary entrainment angle in elastohydrodynamic lubrication elliptical and circular contacts. Proc. Inst. Mech. Eng. Part J J. Eng. Tribol. 234, 424-434 (2019).

\section{Author contributions}

W.Y.Z. and Y.K. designed the research. Y.K. and T.W. performed the analysis. Y.K. wrote the paper. T.W. drawn the images.Y.K., C.X.M. and H.C.Y. revised the manuscript. All authors contributed to writing and fnalizing the manuscript.

\section{Funding}

This research was supported by a special pre-research project of civil aircraft of the Ministry of Industry and Information Technology of China (Grant No.: MJ-2016-D-28) and an Equipped With Pre-research and Sharing Technology Project of China (Grant No.: 4142302021X). 


\section{Competing interests}

The authors declare no competing interests.

\section{Additional information}

Correspondence and requests for materials should be addressed to K.Y.

Reprints and permissions information is available at www.nature.com/reprints.

Publisher's note Springer Nature remains neutral with regard to jurisdictional claims in published maps and institutional affiliations.

(c) (1) Open Access This article is licensed under a Creative Commons Attribution 4.0 International License, which permits use, sharing, adaptation, distribution and reproduction in any medium or format, as long as you give appropriate credit to the original author(s) and the source, provide a link to the Creative Commons licence, and indicate if changes were made. The images or other third party material in this article are included in the article's Creative Commons licence, unless indicated otherwise in a credit line to the material. If material is not included in the article's Creative Commons licence and your intended use is not permitted by statutory regulation or exceeds the permitted use, you will need to obtain permission directly from the copyright holder. To view a copy of this licence, visit http://creativecommons.org/licenses/by/4.0/.

(C) The Author(s) 2021 